\section{Should rosuvastatin be withdrawn from the market?}

Sidney Wolfe (June 26, p 2189) ${ }^{1}$ pleads for the removal of rosuvastatin from the market, suggesting an increased risk of proteinuria and haematuria with increased rosuvastatin dose, as well as a possibly higher rate of rhabdomyolysis than with other drugs. AstraZeneca has launched an extensive marketing campaign to promote the drug as the most potent statin available, which has led to a debate about promotional activities by pharmaceutical companies. ${ }^{2}$ Results of studies $^{3}$ indicate that newly marketed drugs are often prescribed by only a small proportion of doctors, and possibly channelled into an idiosyncratic group of patients. In view of the controversy that surrounds rosuvastatin, we believe the attitude of doctors towards prescribing of the drug should be assessed, and the first users of the drug identified.

Here, we present medication history data for the period January, 1999, to December, 2003, from 123 community pharmacies, representing about a million inhabitants of the Netherlands, linked to detailed information of 195 family doctors from 104 practices. ${ }^{4,5}$ In the 9 months after its introduction in March, 2003, onto the Dutch market, rosuvastatin had a total market share of $5 \%$ of all prescriptions for statins. By December, $2003,35 \%$ of all patients in which statin therapy was initiated or changed, had been prescribed rosuvastatin. We identified 599 patients in whom rosuvastatin was prescribed during our study period, of whom 251
(42\%) had not previously used lipidlowering drugs (table). Most of the patients (67\%) used a maximum daily dose of $10 \mathrm{mg}$, and only two individuals used a daily dose of $80 \mathrm{mg}$. Rosuvastatin is not recommended for patients with predisposing factors for myopathy or rhabdomyolysis, including concurrent use of fibrates, hypothyroidism, and age older than 70 years. However, we noted concurrent fibrate use in 14 patients (2\%), concurrent levothyroxine use in four patients $(0.7 \%)$, and 124 patients (21\%) were aged older than 70 years. 137 (23\%) patients on rosuvastatin therefore had additional risk factors for rhabdomyolysis, and for 50 (37\%) of those rosuvastatin was the first lipidlowering drug used.

We noted a rapid adoption of rosuvastatin by prescribers. In more than a third of all decisions to initiate a (new) statin therapy, the newest drug on the market was chosen, not only for patients with lack of effect on previous lipid-lowering drugs, but for more than $40 \%$ of patients new to lipid-lowering treatments. More than $90 \%$ of patients used rosuvastatin at a maximum daily dose of $10 \mathrm{mg}$ or $20 \mathrm{mg}$, limiting the renal risk associated with higher doses. However, at least $23 \%$ of patients who used rosuvastatin had additional risk factors for myopathy or rhabdomyolysis. Given the yet unproven safety record of rosuvastatin, we are concerned that family doctors and specialists are so keen to prescribe it, even to individuals with no previous experience with lipid-lowering drugs, and to some who have predisposing risk-factors for a potentially lethal side-effect.
Stefan R Florentinus,

*Eibert R Heerdink, OlafH Klungel, Anthonius de Boer

\section{E.R.Heerdink@pharm.uu.nl}

Department of Pharmacoepidemiology and

Pharmacotherapy, Utrecht Institute for Pharmaceutical Sciences, PO Box 80082 , 3508 TB Utrecht, Netherlands

1 Wolfe SM. Dangers of rosuvastatin identified before and after FDA approval. Lancet 2004; 363: 2189-90.

2 The Lancet. The statin wars: why AstraZeneca must retreat. Lancet 2003; 362: 1341.

3 Leufkens HG, Urquhart J. Prescriber profile and postmarketing surveillance. Lancet 1993; 342: 1178.

4 Tinke JL, Griens AMGF. SFK: data en feiten, 2003. Den Haag: SFK, 2003.

5 Otters HBM, van der Wouden JC, Schellevis FG, van Suijlekom-Smit LWA, Koes BW. Trends in prescribing antibiotics for children in Dutch genereal practice. J Antimicrob Chemother 2004; 53:361-66.

In his letter, ${ }^{1}$ Sidney Wolfe reiterates previous allegations with respect to the safety profile of rosuvastatin, and dismisses the effectiveness of the product. I wish to provide an alternative view based on data that I have had the privilege to review as an investigator in the rosuvastatin clinical trial programme and on knowledge I have obtained as part of an authorship group, reporting on the safety of rosuvastatin. ${ }^{2}$

Data from clinical trials show that rosuvastatin has a positive benefit-risk profile across its dose range. In terms of benefit, the clinical advantages of lowering total and LDL-cholesterol concentrations are well established across the class of statin drugs. Emerging data also suggest the clinical benefits of raising $\mathrm{HDL}$-cholesterol and lowering non-HDL-cholesterol values beyond LDL-cholesterol. Rosuvastatin is the most effective statin for lower-

\begin{tabular}{|c|c|c|c|c|c|}
\hline & \multicolumn{4}{|c|}{ Maximum daily dose rosuvastatin } & \multirow{2}{*}{$\begin{array}{l}\text { Total } \\
\text { (599) }\end{array}$} \\
\hline & $10 \mathrm{mg}(\mathrm{n}=404)$ & $20 \mathrm{mg}(\mathrm{n}=146)$ & $40 \mathrm{mg}(\mathrm{n}=47)$ & $80 m g(n=2)$ & \\
\hline No previous use of lipid-lowering drugs & $198(49 \%)$ & $46(32 \%)$ & $7(15 \%)$ & 0 & $251(42 \%)$ \\
\hline Prescribed by specialist & $157(39 \%)$ & $81(56 \%)$ & $32(68 \%)$ & $1(50 \%)$ & $271(45 \%)$ \\
\hline Aged older than 70 years & $97(24 \%)$ & $22(15 \%)$ & $5(11 \%)$ & 0 & $124(21 \%)$ \\
\hline Concomitant use of fibrates & $5(1 \%)$ & $6(4 \%)$ & $3(6 \%)$ & 0 & $14(2 \%)$ \\
\hline Concomitant use of levothyroxine & 0 & 0 & $4(9 \%)$ & 0 & $4(0.7 \%)$ \\
\hline
\end{tabular}


ing total cholesterol, LDL-cholesterol, and non-HDL-cholesterol, ${ }^{3}$ thereby enabling more patients to attain their recommended treatment goals, according to guidelines. As the most extensively studied statin submitted for initial regulatory approval, with 12400 patients who received rosuvastatin $5-40 \mathrm{mg}$ in the phase II/III programme, representing more than 12000 patient-years of exposure, ${ }^{2}$ the efficacy profile of rosuvastatin combined with a large safety database that shows a safety profile similar to those of the other marketed statins completes the basis for this positive benefit-risk association.

More than 42000 patients have participated in clinical trials of rosuvastatin, including several ongoing clinical outcomes trials for which I am an investigator, wherein safety monitoring is consistent with the registration database. The data collected from AstraZeneca's consolidated clinical trials database and postmarketing surveillance programme indicate that rosuvastatin, when used as recommended in approved product labelling, ${ }^{4}$ has a safety profile similar to other marketed statins.

Public Citizen selectively cites case counts of adverse drug reactions, notably for rhabdomyolysis, a rare but potentially fatal complication that arises with all statins. This point was emphasised in a statement by the Dutch Medicines Evaluation Board on their website (http://www.cbg-meb. $\mathrm{nl} / \mathrm{uk} /$ nieuws/index.htm), in response to Wolfe's letter. The statement reads: "The article contains information that is already known to the Board and has been taken into consideration in the evaluation of this product. The Board is of the opinion that Crestor [rosuvastatin] is an effective and safe cholesterol-lowering agent provided that it is used at the recommended dosage and that the precautions stated in the product information are taken into consideration." I personally find this statement reassuring and consistent with my own review of the considerable data available to me.
In my own practice in Amsterdam, where I care for a large number of patients with dyslipidaemia and high LDL-cholesterol, I can attest to the importance of aggressive lipid-lowering therapy. Guidelines establishing recommended treatment goals for patients with dyslipidaemia are widely cited as important tools for reducing cardiovascular morbidity and mortality. Rosuvastatin is effective in enabling my patients to achieve the goals listed in the guidelines and, thus, addresses an important, unmet medical need. The misrepresentation of the benefit-risk profile of this important addition to the pharmacopoeia does the medical community a disservice. This wrangling creates a great deal of unrest among my patients, leading to discontinuation of statin therapy and all the dangerous consequences of such behaviour.

JK has given presentations on the efficacy and safety of rosuvastatin at AstraZeneca symposia

\section{John J P Kastelein}

\section{e.vandongen@amc.uva.n}

Academic Medical Center, University of Amsterdam, Meibergdreef 9, 1105 Amsterdam, Netherlands

1 Wolfe SM. Dangers of rosuvastatin identified before and after FDA approval. Lancet 2004; 363: 2189-90.

2 Shepherd J, Hunninghake DB, Stein EA, et al. The safety of rosuvastatin. AmJ Cardiol 2004; 94: 36-45.

3 Jones $\mathrm{PH}$, Davidson MH, Stein EA, et al. Comparison of efficacy and safety of rosuvastatin versus atorvastatin, simvastatin, and pravastatin across doses (STELLAR trial). AmJ Cardiol 2003; 92: 152-60.

4 Electronic Medicines Compendium. Summary of product characteristics for rosuvastatin calcium. http://emc.medicines.org.uk/ emc/industry/default.asp?page=displaydoc.asp \&documentid=11976 (accessed Aug 26, 2004).

\section{Author's reply}

Stefan Florentinus and colleagues refer to the heavily financed launch of rosuvastatin as the "most potent statin". A previously approved statincerivastatin-was more potent than rosuvastatin, but has been banned. The highest dose of cerivastatin marketed was $0.8 \mathrm{mg}$; the drug was about 100 times more potent, mg for mg, than other statins approved at the time. Its potency was not limited to LDL-cholesterol lowering, however, but extended to an increased rate of rhabdomyolysis, reported by the FDA to be 15-60 times more common than with other drugs in the same class. ${ }^{1}$ Rosuvastatin is also more potent, in both LDL-cholesterol-lowering ability and rhabdomyolysis, than other marketed statins. However, evidence presented at the July 8, 2003, FDA advisory committee meeting indicated that a four-fold higher dose of atorvastatin $(40 \mathrm{mg})$ would result in similar LDL-lowering capabilities to those seen with rosuvastatin $10 \mathrm{mg}$. Rhabdomyolysis was associated with rosuvastatin before approval. However, the rate of this adverse effect could be even greater than at first thought; since approval, the FDA has received reports of many additional US cases of rhabdomyolysis, increasing the total to 65 cases in the USA alone. ${ }^{2}$

I agree with Florentinus and colleagues that rosuvastatin has an unproven safety record, and worry about their evidence of its widespread use in people with an increased risk for rhabdomyolysis. They state that the incidence of proteinuria and haematuria in the clinical trials examined was only increased in individuals taking rosuvastatin $40 \mathrm{mg}$ or $80 \mathrm{mg}$, and that most patients take a maximum daily dose of $10 \mathrm{mg}$ or $20 \mathrm{mg}$, thereby limiting the renal risk associated with high doses. However, as noted in my letter, most reported postmarketing cases of primary renal failure (not secondary to rhabdomyolysis) have been in patients on rosuvastatin $10 \mathrm{mg}$.

John Kastelein complains that the negative information published about rosuvastatin, with its "misrepresentation of the benefit-risk profile" could be dissuading doctors and patients from using the drug and other statins. If there is a misrepresentation of the benefit-risk profile of rosuvastatin, it is by Kastelein (and AstraZeneca) who overstate the benefits and understate the risks. As mentioned above, higher doses of other statins can achieve the same LDL-lowering effects. The unique toxicity of rosuvastatin, including a 
higher rate of rhabdomyolysis and primary renal tubular damage, ${ }^{3}$ belie Kastelein's assertion that rosuvastatin "has a safety profile similar to those of the other marketed statins."

The restriction on reimbursement of rosuvastatin by large US health insurers, such as WellPoint, and by regional health authorities in Sweden, one of AstraZeneca's home countries, indicates that others are concerned about its safety. As the Pharmacy Director of WellPoint, Robert Seidman, stated in explaining their restrictions with respect to rosuvastatin, "We've already been Baycolled." ${ }^{\prime 4}$ In Sweden, regional governmental drug advisers recommended against the use of the drug, noting that newer drugs such as rosuvastatin do not meet the criteria of documented safety and cost-effectiveness. ${ }^{5}$

\section{Sidney M Wolfe swolfe@citizen.org}

Public Citizen's Health Research Group, 1600 20th Street Northwest, Washington, DC 20009, USA

1 Chang JT, Staffa JA, Parks M, Green L. Rhabdomyolysis with HMG-CoA reductase inhibitors and gemfibrozil combination therapy. Pharmacoepidemiol Drug Safety 2004; 13: 417-26.

2 US Food and Drugs Administration. Adverse events reporting systems (AERS) reports for rosuvastatin from US approval through Aug 26, 2004. Rockville: FDA, Aug 26, 2004.

3 Wolfe SM. Dangers of rosuvastatin identified before and after FDA approval. Lancet 2004; 363: 2189-90.

4 Biddle F. Insurer will not corn Crestor. Delaware News Journal, Oct 2, 2003 http:// www.delawareonline.com/newsjournal/local/ 2003/10/02 insurerwillnotc.html (accessed Aug 30, 2004)

5 Anon. Swedes shun Crestor but AstraZeneca denies setback. Reuters, Oct 3, 2003 (www.forbes.com/home_europe/newswire /2003/rtr1099004.html (accessed Aug 30, 2004).

I would like to comment on Sydney Wolfe's appeal ${ }^{1}$ to the US FDA to remove rosuvastatin from the US market. Half of the adverse events reported in his petition-including rhabdomyolysis, renal tubular necrosis, and acute renal failure-involve individuals taking a $10 \mathrm{mg}$ dose of rosuvastatin, which AstraZeneca state is a safe starting dose. ${ }^{2}$
I concur with Blenkinsopp ${ }^{3}$ that too high a dose range for rosuvastatin has been proposed by the company. The company's recommendation for the initial dose is $10 \mathrm{mg}$, which reduces LDL-cholesterol by an average of $46-52 \%$. This reduction far exceeds the recommendation by the National Cholesterol Education Program ${ }^{4}$ of a $30-40 \%$ reduction in LDL-cholesterol for high-risk patients. Indeed, the lowest dose of rosuvastatin that is marketed, $5 \mathrm{mg}$, reduces LDL-cholesterol by $45 \%$ on average, still more than initially necessary for many patients.

Not mentioned in the recent ATP3 guidelines ${ }^{4}$ is the fact that $2.5 \mathrm{mg}$ and $1 \mathrm{mg}$ of rosuvastatin reduce LDL-cholesterol by an average of $42 \%$ and $34 \%$, respectively. ${ }^{5}$ These doses therefore seem adequate to me when starting high-risk patients on rosuvastatin. However, even such low doses could be excessive for people in the moderate risk categories whose LDL-cholesterol only needs to be reduced by 20-30\%.

Most adverse effects of statins are dose-related. Optimum treatment depends on the use of the lowest therapeutic dose for each patient. Unfortunately, AstraZeneca does not produce a $2.5 \mathrm{mg}$ or a $1 \mathrm{mg}$ dose of rosuvastatin and does not provide any information about the effectiveness of these doses in the product labelling. By denying doctors and patients this information, the manufacturer hampers our ability to match treatment to the specific amount of LDL-cholesterol reduction needed by millions of patients.

The development of lower, proveneffective, safer doses of rosuvastatin would benefit not only patients and their doctors, but also the manufacturer. The health-care system might also benefit from lower drug costs and fewer adverse events than at present.

\section{Jay S Cohen}

\section{jacohen@ucsd.edu}

Departments of Family and Preventive Medicine and of Psychiatry, University of California, San Diego, USA
1 Wolfe SM. Petition to the FDA to remove the cholesterol-lowering drug rosuvastatin (Crestor) from the market. http://www. citizen.org/publications/release.cfm?ID=7305 (accessed Aug 31, 2004).

2 Olsson G. Safety and efficacy of rosuvastatin. Lancet 2004; 364: 135

3 Blenkinsopp J. The statin wars. Lancet 2003; 362: 1854.

4 Grundy SM, Cleeman JI, Bairey CN, et al. Implications of recent clinical trials for the National Cholesterol Education Program Adult Treatment Panel III Guidelines. Circulation 2004; 110: 227-39.

5 Olsson AG, Pears J, McKellar J, et al. Effect of rosuvastatin on low-density lipoprotein cholesterol in patients with hypercholesterolemia. Am J Cardiol 2001; 88: 504-08.

\section{Company's reply}

Statins represent one of the most important advances in the management of patients at risk for cardiovascular disease during the past decades. The benefits of lowering LDL cholesterol have been established across the class in a broad population of patients, and are reflected in international treatment guidelines. ${ }^{1}$ Completed trials have provided evidence that additional benefit accrues even at concentrations of LDL cholesterol well below current treatment goals, resulting in proposals for even more stringent guidelines for those patients at highest risk. ${ }^{2}$ Thus, the medical need for even more effective drugs in this class is not questioned, and the introduction of such drugs is of import, provided a favourable balance between benefit and risk is shown. AstraZeneca therefore welcomes an open and balanced discussion of rosuvastatin and the results obtained in our clinical and postmarketing surveillance programmes. Towards this end, we have made the results of our completed clinical trials, including those that supported the initial registration, freely available worldwide at http://www.rosuvastatin information.com/.

Your correspondents correctly state that statins are associated with doserelated muscle effects, including rhabdomyolysis. It is essential to recognise that the degree to which different statins' intrinsic ability to lower LDL cholesterol is not related to their 


\section{Correspondence}

\begin{tabular}{|c|c|c|c|}
\hline & $\begin{array}{l}\% \text { patients who } \\
\text { developed } \geqslant 2+ \\
\text { proteinuria }\end{array}$ & $\begin{array}{l}\% \text { patients who } \\
\text { developed } \geqslant 2+ \\
\text { haemoglobinuria }\end{array}$ & $\begin{array}{l}\% \text { patients who devel- } \\
\text { oped } \geqslant 2+\text { protein- } \\
\text { uria and } \geqslant 1+ \\
\text { haemoglobinuria* }\end{array}$ \\
\hline \multicolumn{4}{|l|}{ Placebo } \\
\hline Dose not applicable & $0.6(2$ of 330$)$ & $0.9(3$ of 351$)$ & $0(0$ of 311$)$ \\
\hline \multicolumn{4}{|l|}{$\begin{array}{l}\text { Rosuvastatin } \\
\text { (mg daily) }\end{array}$} \\
\hline 5 & $0.2(1$ of 587$)$ & $1 \cdot 9(11$ of 583$)$ & $0(0$ of 554$)$ \\
\hline 10 & $0.6(6$ of 1008$)$ & $1.4(15$ of 1057$)$ & $0(0$ of 946$)$ \\
\hline 20 & $0.7(6$ of 872$)$ & $1 \cdot 2(11$ of 914$)$ & $0(0$ of 836$)$ \\
\hline 40 & $1 \cdot 2(22$ of 1850$)$ & $1 \cdot 8(33$ of 1852$)$ & $0 \cdot 3(6$ of 1765$)$ \\
\hline \multicolumn{4}{|l|}{$\begin{array}{l}\text { Atorvastatin } \\
\text { (mg daily) }\end{array}$} \\
\hline 10 & 0.5 (3 of 628) & $1 \cdot 1(7$ of 662$)$ & $0(0$ of 605$)$ \\
\hline 20 & $0.5(2$ of 438$)$ & $1.8(8$ of 452$)$ & $0.2(1$ of 422$)$ \\
\hline 40 & $0(0$ of 63$)$ & $0(0$ of 64$)$ & $0(0$ of 54$)$ \\
\hline 80 & $0.3(1$ of 342$)$ & $1 \cdot 7(6$ of 354$)$ & $0(0$ of 311$)$ \\
\hline \multicolumn{4}{|l|}{$\begin{array}{l}\text { Simvastatin } \\
\text { (mg daily) }\end{array}$} \\
\hline 20 & $1 \cdot 1(5$ of 452$)$ & $1.0(5$ of 477$)$ & $0.2(1$ of 431$)$ \\
\hline 40 & $0 \cdot 3$ (1 of 314) & $2 \cdot 4(8$ of 331$)$ & 0.3 (1 of 304) \\
\hline 80 & $0(0$ of 325$)$ & $2 \cdot 8(9$ of 321$)$ & $0(0$ of 312$)$ \\
\hline \multicolumn{4}{|l|}{$\begin{array}{l}\text { Pravastatin } \\
\text { (mg daily) }\end{array}$} \\
\hline 20 & $0.6(1$ of 162$)$ & $1 \cdot 2(2$ of 163$)$ & $0.7(1$ of 152$)$ \\
\hline 40 & $0(0$ of 64$)$ & $0(0$ of 63$)$ & $0(0$ of 59$)$ \\
\hline
\end{tabular}

Data from reference 5 . *Data on file. Urine dipstick results reported as $\geqslant 2+$ represent urinary protein concentrations $\geqslant 1 \mathrm{~g} / \mathrm{L}$. Percentage of patients with results that were none or trace at baseline but $\geqslant 2+$ at last scheduled visit used to estimate frequency of developing proteinuria; dipstick results for haemoglobinuria, and proteinuria and haemoglobinuria analysed similarly.

Table: Urinalyses (dipstick) results from patients treated with rosuvastatin and comparator statins consistent with a possible renoprotective effect of rosuvastatin, even in patients with pre-existing renal disease or other risk factors for same.

The clinical experience with rosuvastatin, based on more than 3 million patients being treated, more than 10 million prescriptions, clinical trial data from more than 42000 patients, and ongoing pharmacoepidemiology studies, provides the basis for the current safety assessment of this drug. These data have been shared with regulatory authorities worldwide. Based on review of these data, our conclusion is that rosuvastatin's safety profile is similar to those of the marketed statins. This view of the benefit-risk profile of rosuvastatin is shared by regulatory authorities in the 64 countries where rosuvastatin is approved.

Our opinion is that the introduction of rosuvastatin fulfils an important medical need by providing best-inclass LDL cholesterol reduction and HDL cholesterol increases without introducing additional statin-related concerns, provided that treatment follows prescribing information.

\section{Gunnar O Olsson, *Jonathan C Fox} jonathan.c.fox@astrazeneca.com

Global Cardiovascular Therapy Area, AstraZeneca, Mölndal, Sweden (GOO); and *Clinical Research, AstraZeneca, 1800 Concord Pike, Wilmington DE 19803, USA (JCF)

1 De Backer G, Ambrosioni E, Borch-Johnsen K, et al. European guidelines on cardiovascular disease prevention in clinical practice: third joint task force of European and other societies on cardiovascular disease prevention in clinical practice. Atherosclerosis 2004; 173: 381-91.

2 Grundy SM, Cleeman Il, Merz CN, et al. Implications of recent clinical trials for the National Cholesterol Education Program Adult Treatment Panel III guidelines. Circulation 2004; 110: 227-39.

3 Jones PH, Davidson MH, Stein EA, et al. Comparison of the efficacy and safety of rosuvastatin versus atorvastatin, simvastatin, and pravastatin across doses (STELLAR Trial). Am J Cardiol 2003; 92: 152-60.

4 Shepherd J, Hunninghake DB, Stein EA, et al. Safety of rosuvastatin. Am J Cardiol 2004; 94: 882-88.

5 Vidt DG, Cressman MD, Harris S, Pears JS, Hutchinson HG. Rosuvastatin-induced arrest in progression of renal disease. Cardiology 2004: 102: 52-60.

\section{Discontinuation of Mysoline: lessons to be learned}

Primidone is licensed for the treatment of epilepsy and essential tremor. In April, 2003, AstraZeneca informed the UK Department of Health $(\mathrm{DoH})$ that they were planning globally to discontinue Mysoline, the only primidone licensed in the UK, due to low volume of use. This decision would affect about 10000 individuals in England alone. In June, 2003, the company told regional medicines information centres and the pharmaceutical press in the UK that Mysoline supply would be stopped in December. Further information, cascaded from purchasing pharmacists in hospitals and Primary Care Trusts to individual hospital and family doctors, stated that primidone could be withdrawn and replaced but warned that abrupt withdrawal could cause seizures.

After complaints from several professional and patients' groups, AstraZeneca reviewed their decision and announced on Aug 12, that the drug would be continued into 2004. AstraZeneca announced in June, 2004, that the production and supply of Mysoline was secure for the foreseeable future.

The discontinuation of medicines is not regulated by legislation, but by a set of best-practice guidelines drawn up by the $\mathrm{DoH}$ and the Association of the British Pharmaceutical Industry (ABPI). ${ }^{1}$ Adherence is voluntary. The DoH has no legal means of stopping the discontinuation of a licensed drug.

AstraZeneca followed the guidelines, but this did not protect some patients with epilepsy (see panel for examples). The guidelines imply that the DoH will consult relevant professional and patients' groups before the decision to discontinue a drug is publicly announced. How this consultation was done in this case is unclear, but the process did not involve the Association of British Neurologists, the British Chapter of the International League Against Epilepsy, Epilepsy Action, the National Society for 
Panel: Two examples of patients affected by discontinuation of Mysoline

\section{Case 1}

A 65 -year-old man with epilepsy treated with primidone was invited by his doctor for a review of his medication in September, 2003. The patient was started on primidone after two generalised tonic clonic seizures (GTCS) in 1963, and subsequently had only one further GTCS after an attempt to withdraw primidone in 1973. Although the patient was concerned about making any changes to his treatment, his doctor instructed him to switch to phenytoin over 2 weeks. A fortnight after taking the last tablet of primidone the patient, who lives in an isolated rural location, had a cluster of three GTCS, resulting in the loss of his driving licence for a year.

\section{Case 2}

A 53-year-old woman with epilepsy with GTCS treated with primidone and valproate saw her family doctor for a check-up in November, 2003. She developed epilepsy after a febrile convulsion at age 5 years. Her seizures proved refractory to several drugs before she started primidone monotherapy in 1967, and stopped after valproate was added to primidone in 1977. Valproate monotherapy was abandoned because of recurrent seizures in 1978. At her check up, she was informed of the discontinuation of primidone and told that her treatment would be tapered over 2 months. Less than a month after stopping primidone she had a GTCS, causing her to fall down some stairs. She developed problems with concentration and lightheadedness, which meant she was unable to work.

Epilepsy, or the Joint Epilepsy Council. What lessons can be learned? The $\mathrm{DoH}$ and $\mathrm{ABPI}$ should review their guidelines; they might offer better protection if the consultation process about planned drug discontinuations was improved and clear standards for the dissemination of information were laid down. The DoH could also review its policy on informing interested parties on the procurement of discontinued medicines from abroad. Pharmaceutical companies should liaise with professional and patients' groups before discontinuing a drug, and Primary Care Trusts should review how they disseminate information received from pharmaceutical companies or the DoH to family doctors. Finally, doctors who are not experts in the treatment of epilepsy should not change drug regimens without obtaining specialist advice.

Copies of all dated correspondence from AstraZeneca are available from the author.

\section{Markus Reuber} mreuber@doctors.org.uk

Royal Hallamshire Hospital, Sheffield S10 2JF, UK
1 Association of the British Pharmaceutical Industry and Department of Health. Ensuring best practice in the notification of product discontinuations: best practice guidelines. http://www.dh.gov.uk/assetRoot/04/06/ 70/45/04067045.pdf (accessed July 30, 2004).

\section{Company's reply}

AstraZeneca, like all pharmaceutical companies, reviews its product portfolio on an ongoing basis. As a result of one of these reviews, we took the decision to discontinue various products for which there was a low demand or supply was unreliable. Part of this decision was to discontinue the manufacturing and marketing of Mysoline at a global level.

After this decision, AstraZeneca UK reviewed the need for primidone in the UK. After consulting with the $\mathrm{DoH}$, we followed their guidelines for the discontinuation of medicinal products. In accordance with the guidelines, AstraZeneca UK proactively communicated its intentions to wholesalers, senior hospital pharmacists, and the pharmaceutical press in early June, 2003.
In hindsight, consultation with those doctors who treat patients with Mysoline in the UK might also have been beneficial. However, once concerns were raised about the withdrawal of the drug by the medical community and patients, we immediately took steps to address the situation. We liaised with advisers, including consultant neurologists and a family doctor with special interest in epilepsy on how to best inform stakeholders of the supply situation. We immediately notified UK neurologists through the Association of British Neurologists. We contacted key patient groups directly and worked in conjunction with them to notify patients-ie, used web sites, newsletters. We sent notification to neurologists and family doctors via a commercial list widely used in the industry and acknowledged to be the most up-to-date and comprehensive available. We used our medical information team to answer queries from health-care professionals and patients. We undertook ongoing communications with the DoH, professional organisations, and patients' groups to advise regarding the extended supply of Mysoline.

As an ethical pharmaceutical company we are committed to high standards of patient care. We took the concerns about the withdrawal of Mysoline seriously and decided to extend its supply in the UK until an alternative supplier was secured. In June, 2004, Acorus Therapeutics agreed to continue the supply of Mysoline to the UK.

As this process has evolved, we have learned that proactive communication between the relevant parties-industry, DoH, the medical community, and patients-is essential to ensure the safe withdrawal of pharmaceutical products. AstraZeneca is committed to working in partnership with the medical community throughout all stages of a drug's life-cycle, including those situations where availability of more advanced
Rights were not granted to include this image in electronic media. Please refer to the printed journal. 


\section{Correspondence}

treatments and evolving medical practice lead to declining use, raising the issue of product withdrawal. In this spirit, we are also willing to work with the $\mathrm{DoH}$ and $\mathrm{ABPI}$ to review the guidelines to ensure product withdrawals are done responsibly and directed by the needs of patients.

Rhiannon Rowsell rhiannon.rowsell@astrazeneca.co.uk

AstraZeneca UK, Horizon Place, Luton, Bedfordshire LU1 3LU, UK

\section{The Tailor of Gloucester: a jacket for the Marfan's aorta}

Much is known about the genetic abnormalities that result in the various patterns of fibrillin deficiencies that constitute the Marfan's phenotype, but the life-threatening manifestation is the aortic root abnormality in which the proximal aorta dilates and is prone to dissection and rupture.

Patients are offered regular echocardiographic monitoring with eventual replacement of the aortic root (with or without the aortic valve), according to criteria based on absolute size, rate of change, and family history. ${ }^{1,2}$ As aortic root surgery has become safer surgeons have felt entitled to offer replacement earlier in the progression. ${ }^{3}$ However, this involves major surgery. If the valve is replaced (the standard and most
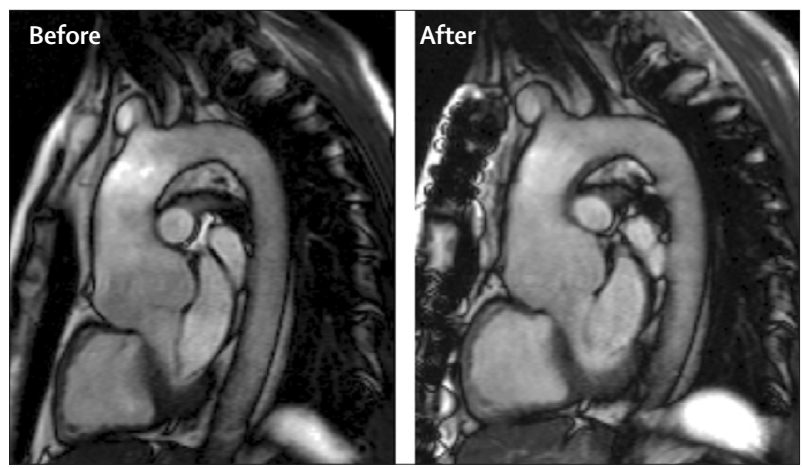

Figure: Diastolic steady-state in free precession (white blood) image acquired in oblique sagittal plane before and after insertion of external aortic root support (EARS) Thickening of aortic wall by the support is just appreciable on post EARS image and is seen extending to proximal aortic arch. durable surgical solution) life-time anticoagulation is mandatory; if the valve is conserved there is the fear of failure with the need for future surgery.

An attractively conservative alternative, suggested many years ago by Robicsek, ${ }^{4,5}$ is to wrap the aorta externally to prevent expansion. However, in the context of an already dilated aorta, the compromise of a hand-tailored external support at a time when off the shelf composite valve conduits were becoming available was worrying and not adopted in the main. ${ }^{3}$ Computer aided design and rapid prototyping has allowed us to revisit that idea. The digital information from magnetic resonance imaging (MRI) can be used to create a replica of the patient's aorta, on which can be formed an external support matching exactly the contours of the aorta, including the sinuses and the coronary artery origins.

Our first patient is a 47-year-old man with Marfan's syndrome. His aortic dimensions increased from $4.4 \mathrm{~cm}$ in 1991 to $4.9 \mathrm{~cm}$ in 2003 . For the past 3 years he has taken atenolol $50 \mathrm{mg}$ and bendrofluazide $5 \mathrm{mg}$ daily in an attempt to stabilise his aorta and slow the rate of expansion. After agreement from the hospital clinical practice committee, we operated on May 24, 2004. We used a midline sternotomy and a brief period (21 min) of cardiopulmonary bypass, which we envisage will not be necessary in the future. We dissected the aorta to below the coronary arteries and applied the tailored graft to the aortic root and ascending aorta. Proximally, we made holes in the graft to accommodate the left and right coronary ostia without compromising flow. The graft was secured at the ventriculoarterial junction at six equidistant points. Distally, the graft was placed around the origin of the brachiocephalic trunk. We used intraoperative transoesophageal echocardiography throughout the 2.5-h procedure to check for normal coronary flow and aortic valve function. The patient was discharged after 6 days. 3 months postoperatively he is leading an active life. The postop- erative MRI scan done on Sept 2, 2004, barely discerns the external support (figure). The valve and endothelium in contact with the blood are biologically completely unchanged.

An idea that did not hold sway when first suggested has come to fruition. A fitted external aortic root support, derived from non-invasive imaging data overcomes the technical obstacles and achieves complete valve sparing, avoids anticoagulation, and can be done without opening the aorta.

We thank Robert $\mathrm{H}$ Anderson for advice and encouragement. We are indebted to many at the Royal Brompton Hospital for making this innovative surgery possible.

Tal Golesworthy, Michael Lampérth, Raad Mohiaddin, John Pepper, Warren Thornton, *Tom Treasure Tom.treasure@ukgateway.net

Environmental Development Technology, Tewkesbury, Gloucestershire, UK (TG); Mechanical Engineering Department, Imperial College London, London, UK (ML, WT); Royal Brompton Hospital, London, UK (RM); National Heart and Lung Institute, London, UK (JP); *Guy's Hospital, London SE1 9RT, UK (TT)

1 Treasure T. Elective replacement of the aortic root in Marfan's syndrome. Br Heart J 1993; 69: 101-03.

2 Treasure T, Chow T, Gallivan S. Replacement of the aortic root in Marfan's syndrome. N Engl J Med 1999; 341: 1473-74.

3 Gott VL, Greene PS, Alejo DE, et al Replacement of the aortic root in patients with Marfan's syndrome. N EnglJ Med 1999; 340: 1307-13.

4 Robicsek F, Thubrikar MJ. Conservative operation in the management of annular dilatation and ascending aortic aneurysm. Ann Thorac Surg 1994; 57: 1672-74.

5 Bentall H, De Bono A. A technique for complete replacement of the ascending aorta. Thorax 1968; 23: 338-39.

\section{Department of Error}

Holly. IGF-1, IGFBP-3, and cancer risk. Lancet 2004; 364: 325-26-In this Correspondence letter (July 24), the third sentence of paragraph four should be: "For example, in the case of premenopausal breast cancer ..."

Lewin MR, Knott P, Lo M. Seal finger. Lancet 2004; 364: 448-In this Clinical Picture (July 31), the elephant seal should be identified as Mirounga angustirostris. 